Introduction Poorer populations bear a disproportionate burden of avoidable mortality from road traffic injuries.

Aims and Methods Data collected by the World Health Organization on road traffic victims among the countries of the WHO European Region were used to analyze the distribution of road traffic injury deaths by road user category and whether such distribution is correlated to the income level of a country.

Results Vulnerable road users (pedestrians, cyclists, motorcyclists) account for $39 \%$ of road traffic deaths in the WHO European Region; this figure is slightly less that the global figure of $46 \%$. The distribution of vulnerable road users within the Region notably differs. Greece, Malta, Cyprus, Italy and France have the highest proportions of deaths of motorised two-wheeler users among victims of road crashes, exceeding 1 in 4 deaths. Pedestrians make up 18\% of all road crash deaths in the European Union, but this is three times higher for the Commonwealth of Independent States (CIS countries). CIS countries have urban speed limits of $60 \mathrm{~km} / \mathrm{h}$. There is a strong inverse correlation between the proportion of pedestrians killed and gross national income per person $(r=-0.66)$. This may be partly explained by changing modes of transport with country income, but also has implications for infrastructure development and speed control enforcement to protect pedestrians in low- and middle-income countries (LMICs).

Conclusion Road safety stakeholders need to work together to implement evidence-based action to guarantee better protection for vulnerable road users, especially pedestrians in LMICs.

\section{REPRIORITISING TRANSPORT POLICIES TO PROTECT VULNERABLE ROAD USERS: THE SITUATION IN THE WHO EUROPEAN REGION}

F Zambon*, D Sethi, F Racioppi Correspondence: World Health Organization, WHO Regional Office for Europe, 00187, Italy 